\title{
Association between professional qualification and adverse events in neonatal and pediatric intensive treatment units
}

\author{
Associação entre qualificação profissional e eventos adversos em \\ unidades de tratamento intensivo neonatal e pediátrico \\ Asociación entre calificación profesional y eventos adversos en \\ unidades de tratamiento intensivo neonatal y pediátrico
}

\section{Eliane Cristina Sanches Maziero ${ }^{a}$ Elaine Drehmer de Almeida Cruz ${ }^{\mathrm{b}}$ Josemar Batista ${ }^{a}$ Francine Taporosky Alpendre ${ }^{a}$ Marilise Borges Brandãoc Elias Teixeira Krainskid}

\section{How to cite this article:} Maziero ECS, Cruz EDA, Batista J, Alpendre $\mathrm{FT}$, Brandão MB, Krainski ET. Association between professional qualification and adverse events in neonatal and pediatric intensive treatment units. Rev Gaúcha Enferm. 2021;42:e20210025. doi: https://doi.org/10.1590/19831447.2021 .20210025
- Universidade Federal do Paraná (UFPR). Programa de Pós-Graduacăo em Enfermagem. Curitiba Paraná, Brasil.

Universidade Federal do Paraná (UFPR). Departamento de Enfermagem. Curitiba, Paraná, Brasil.

Universidade Federal do Paraná (UIPR). Complexo Hospital de Clínicas da Universidade Federal do Paraná. Curitiba, Paraná, Brasil.

¿ Universidade Federal do Paraná (UFPR) Departamento de Estatística. Curitiba, Paraná, Brasil.

\section{ABSTRACT}

Objective: to verify the association between the qualification of nursing professionals and the occurrence of adverse events in neonatal and pediatric intensive care units.

Method: Cross-sectional and evaluation study conducted in six intensive care units of five public hospitals in the state of Paraná, Brazil. Data was collected from April/2017 to January/2018 through the use of a questionnaire to be completed by 143 nursing professionals and retrospective analysis of 79 medical records using the Neonatal Trigger Tool and Pediatric Trigger Tool instruments. The prognostic factors were professional training and the existence, or not, of a continuing education service; analysis was performed by logistic regression. Results: Detected 30 adverse events in 22 medical records analyzed. There was a prevalence of infection $(n=12 ; 40 \%)$ and skin damage $(n=9 ; 30 \%)$. Among the prognostic factors, continuing education was identified as a protective factor against adverse events $(p \leq 0.05)$. Conclusion: Continuing education was associated with the prevention of adverse events in neonatal and pediatric intensive care units.

Keywords: Intensive care units, neonatal. Intensive care units, pediatric.Credentialing. Patient harm. Patient safety.

\section{RESUMO}

Objetivo: Verificar a associação entre a qualificação dos profissionais de enfermagem e a ocorrência de eventos adversos em unidades de terapia intensiva neonatal e pediátrica.

Método: Estudo transversal conduzido em seis unidades de cinco hospitais públicos do Estado do Paraná, Brasil. A coleta de dados ocorreu de abril/2017 a janeiro/2018, com análise retrospectiva e aplicação dos instrumentos Neonatal Trigger Tool e Paediatric Trigger Tool a 79 prontuários, para detectar eventos adversos, questionário autoaplicável a 143 profissionais e consulta aos documentos e registros hospitalares. Os fatores prognósticos de eventos adversos foram capacitação profissional e existência, ou não, de serviço de educação continuada; a análise foi realizada por regressão logística.

Resultados: Detectou-se 30 eventos adversos, com prevalência de infecção $(n=12 ; 40 \%)$ e lesão de pele $(n=9 ; 30 \%)$. A educação continuada foi identificada como fator protetor para eventos adversos $(p \leq 0,05)$.

Conclusão: atividade educativa foi associada à prevenção de eventos adversos em unidades de terapia intensiva neonatal e pediátrica. Palavras-chave: Unidades de terapia intensiva neonatal. Unidades de terapia intensiva pediátrica. Credenciamento. Dano ao paciente. Segurança do paciente.

\section{RESUMEN}

Objetivo: Verificar la asociación entre la calificación de los profesionales de enfermería y la ocurrencia de eventos adversos en las unidades de cuidados intensivos neonatales y pediátricos

Método: Estudio evaluativo y transversal, realizado en seis unidades de cuidados intensivos de cinco hospitales públicos del estado de Paraná, Brasil. La recolección de datos se llevó a cabo de abril / 2017 a enero / 2018 con la aplicación de un cuestionario a 143 profesionales de enfermería y análisis retrospectivo de 79 historias clínicas utilizando los instrumentos Neonatal Trigger Tool y Pediatric Trigger Tool. Los factores pronósticos fueron la formación profesional y la existencia, o no, de un servicio de educación continua; el análisis se realizó mediante regresión logística.

Resultados: Detectado 30 eventos adversos en 22 historias clínicas analizadas. Hubo una prevalencia de infección $(n=12 ; 40 \%)$ y daño cutáneo $(n=9 ; 30 \%)$. Entre los factores pronósticos, se identificó la educación continua como factor protector frente a eventos adversos $(p \leq 0,05)$.

Conclusión: La educación continua se asoció con la prevención de eventos adversos en las unidades de cuidados intensivos neonatales y pediátricos.

Palabras clave: Unidades de cuidado intensivo neonatal. Unidades de cuidado intensivo pediátrico. Habilitación profesional. Daño del paciente. Seguridad del paciente. 


\section{口INTRODUCTION}

Neonatal intensive care units (NICU) provide care to patients aged from zero to 28 days; pediatric intensive care units (PICU) are for patients aged from 29 days to 14 years old; and mixed pediatric intensive care units (MPICU) where both neonates and children are admitted, though in separate areas, and stand out for the complexity of their needs and critical condition of their clientele ${ }^{(1)}$.

In the aforementioned areas, the use of various technologies, care associated to a critical clinical condition, work overload, non-compliance with guidelines and care protocols and the inadequate transition of neonatal and pediatric patient care maximize the cases of adverse events (AE) ${ }^{(2)}$. These are defined as care-related incidents that result in harm to the patient ${ }^{(3)}$.

Studies aimed to investigate AEs in NICUs and PICUs show the vulnerability of this population to health risks. A survey carried out in 16 hospitals in the United States that analyzed 3,790 medical records identified 19.1 AEs per patient/day, with $50.7 \%$ considered avoidable ${ }^{(4)}$. In Brazil, a study with 190 newborn and pediatric patients admitted to a teaching hospital found $73 \mathrm{AEs}$, mostly cases related to loss of peripherally inserted central catheter ( $n=18 ; 25 \%)$ and phlebitis $(n=12 ; 16 \%)^{(5)}$.

Detection of these events and analysis of their causes contribute to decision making in order to reduce the recurrence of failures ${ }^{(6)}$. The identification of systemic errors helps in the planning of institutional actions and in the construction of public policies related to processes and results, seeking to build a culture of patient safety and ensure improvements in nursing care. However, the existence of several systemic factors that can increase the risk of occurrence of AEs is recognized, such as the imbalance between the workforce, the education/training of nursing professionals and the care demands inherent to the clinical condition of patients ${ }^{(7)}$.

In this regard, the ongoing training of the nursing team for intensive care can have positive effects on outcome indicators, including those concerning patient safety and quality of care ${ }^{(8)}$. Specific knowledge about life support, recognition of normal vital signs and changes in basic age-related physiologic parameters as well as drug dosage based on weight $t^{(9)}$ are required in the care to the neonatal and/or pediatric population.

The development of technical skills and non-technical skills, such as communication and teamwork, is necessary for the identification and management of risks associated with the routine care of the nursing staff in these care scenarios.
It is also one of the first steps to improve the safety culture, in order to reduce serious and preventable $\mathrm{AES}{ }^{(10)}$.

Although all health professionals are affected by AEs, nursing teams, particularly nurses, are primarily responsible for actions to promote patient safety and for the continuity of these practices during patient stay in the hospital ${ }^{(11)}$. Therefore, it is necessary to investigate, characterize and establish the relationship between qualification of professional nurses and AEs, since nursing professionals represent more than half of all health workers at the different health care levels ${ }^{(12)}$

When it is understood that EAs are not limited to individual error, the identification of gaps and factors associated with their occurrence collaborate to promote improvements in structural indicators and processes, allowing the improvement of an organizational safety culture, and hence the provision of excellent care intended by highly reliable organizations. Thus, the present study aimed to verify the association between qualification of nursing professionals and occurrence of adverse events in neonatal and pediatric intensive care units.

\section{METHOD}

Evaluation and cross-sectional study carried out in six ICUs in the State of Paraná, Brazil, located in five state hospitals, including four neonatal ICUS, one pediatric ICU and one mixed pediatric ICU. One of the hospitals is large, and the others are medium-sized. The referred units were selected because they provide services exclusively to Unified Health System (SUS) patients and belong to the State Department of Health. Thus, all professionals are subject to the same work protocols and standards and perform the same duties. Table 1 presents the characteristics of the investigated units.

Two trained nurses from the research team collected data from April 2017 to January 2018, always in the last week of each month in each hospital, in order to systematize the procedure in this study. The chronological order was determined by convenience, due to the physical proximity between the health institutions.

The participants were organized into two groups. Group I was formed by nursing professionals and Group || was composed of all patients with records/medical records who were discharged, transferred to another ward (internal discharge) and/or to another hospital, or died during the period, which was limited to the 30 days prior to the start of data collection. No exclusion criteria were established for this group. 
Table 1 - Profile of the investigated intensive care units. Curitiba, PR, Brazil, 2017-2018

\begin{tabular}{|c|c|c|c|c|c|c|c|}
\hline \multirow{2}{*}{ General Data } & Hospital & 1 & 1 & 2 & 3 & 4 & 5 \\
\hline & ICU & NICU & PICU & NICU & NICU & mPICU & NICU \\
\hline Main characteristic & & Pediatric & Pediatric & General & General & General & General \\
\hline Inauguration of ICU & & 2009 & 2009 & 2011 & 2013 & 2001 & 2009 \\
\hline Total number of beds & & 78 & 78 & 116 & 73 & 222 & 170 \\
\hline Number of beds in the ICU & & 20 & 10 & 10 & 10 & ${ }^{*} 8 / 2$ & 7 \\
\hline \multicolumn{8}{|l|}{ Constituted services } \\
\hline Quality and safety & & $x$ & $x$ & $x$ & $x$ & $x$ & $x$ \\
\hline Infection Control & & $x$ & $x$ & $x$ & $x$ & $x$ & $x$ \\
\hline Continuing Education & & $x$ & $x$ & - & - & $x$ & $x$ \\
\hline
\end{tabular}

Source: Research data.

*Eight pediatric and two neonatal beds

The population of Group I consisted of 203 nursing professionals. The workers included in the work schedule and who were active for at least one day during the data collection period were invited to participate in the study, constituting an intentional or non-probability sample.

Envelopes containing the Informed Consent Form (ICF) and the sociodemographic qualification questionnaire were sent by the researchers to the 172 professionals who accepted the invitation. Twenty-nine (29) professionals who returned the incomplete questionnaires were excluded, and therefore, a total number of 143 professionals participated in the study and were coded as follows: NN for night shift nurses, DN for day shift nurses, NNT for night shift nursing technicians and DNT for day shift nursing technicians.

The search for AEs was done in two steps. Step 1 consisted of identifying potential adverse events ( $P A E$ ) through retrospective consultation of medical records and with the help of clues or triggers available in two AEs search tools $s^{(13-14)}$.

The first tool was the Pediatric Trigger Tool, which features 40 triggers grouped into different aspects or components, namely: general, surgical, intensive care, medication and laboratory tests ${ }^{(13)}$. The second tool was the Neonatal Trigger Tool, which has 28 triggers distributed among general care, medication administration and changes in laboratory tests ${ }^{(14)}$.
Since the versions of these tools were available exclusively in English and had not yet been validated for use in Brazil, a simulation of use was performed prior to data collection. This simulation was performed for five consecutive days in medical records of neonatal and pediatric patients admitted to Hospital 1 and who were not included in the research sample. After the clarification of the doubts related to the understanding of the triggers in the English language and their practical applicability, Step 1, which consisted in data collection by retrospective review of medical records of the research sample, began.

When one or more triggers were identified, data from the pAEs were recorded, for confirmation or not, in the subsequent step of the study. In Step 2, all pAEs were judged by a single pediatrician who worked and had expertise in a patient safety program at a federal teaching hospital and did not have an employment contract with the investigated health units.

Data related to professional qualification were collected through access to information extracted from the self-administered questionnaire: complementary education (graduation for technicians and specialization for nurses) and aspects related to in-person training recorded by the respective services, regardless of the topic addressed.

The questionnaire was designed by the researchers and tested with 10 health professionals who did not participate 
in the study; no adjustments were needed, and the data obtained was not part of the study. Regarding qualification and training, the record of continuing education activities in the institution and the frequency reported by participants in educational activities were considered.

Data were entered into a Microsoft Excel ${ }^{\circledR}$ spreadsheet, analyzed using descriptive statistics and presented in relative and absolute frequencies. The variables related to in-service qualification and education were considered predictors, and AEs were characterized as outcome variables.

For the statistical analysis of the association, logistic regression was performed, with calculation of the Odds Ratio $(\mathrm{OR})$ used to infer the association of professional qualification and in-service education as favorable or unfavorable. OR was calculated by grouping the favorable or unfavorable units and the occurrence of AEs. The significance value adopted was $(p \leq 0.05)$.

The prognostic factors for the occurrence of AEs were considered as a proportion for each of the following groups.

Group 1 - qualification: qualification to work in ICUs, nurses with general postgraduate studies and postgraduate studies in ICUs, graduate nursing technicians, and participation in training activities. Except regarding participation in training, a dichotomous yes/no format was used in the answers. Considering the possible answers regarding the participation in training activities informed (Always, Almost Always and Never), an association was established with the score weight 10 (ten) for Always, weight 0 (zero) for Almost Always and weight -10 (minus ten) for Never.

Group 2 - in-service education: based on the existence, or not, of a formal continuing education service, the answers were of a dichotomous type, the hospital institution had or did not have the service. This was considered the only predictor variable in group 2 .

Regarding ethical aspects, access to the records was previously authorized by the director of each hospital, and the study was approved in accordance with Resolution $466 / 12$ by the Research Ethics Committee, under Protocol no 1.790.695/2016 and CAAE No. 57191516.6.0000.0102 (Universidade Federal do Paraná), and under Protocol no 1.837.653/2016 and CAAE no 57191516.6.3001.5225 (Secretaria do Estado da Saúde do Paraná) Participants in Group 1 signed the ICF (Informed Consent Form). As for the participants in Group 2, they were not required to sign the referred form.

\section{Q RESULTS}

Table 2 shows the association between predictor and outcome variables, considering the occurrence of AEs in each IC.
$R C \leq 1$ and ( $p \leq 0.05)$ was obtained in statistical analysis of the association between predictive factors related to qualification and occurrence of AEs for the existence of a Continuing Education Service. This finding suggests that the referred Service is a predictor of protection against the occurrence of AEs. No association was found with the occurrence of AEs for the other factors.

The study sample consisted of 143 nursing professionals, representing $70.44 \%$ of the target population. Of these, 34 (23.8\%) were nurses and 109 (76.2\%) were nursing technicians. There were 27 members of the nursing staff in qualification programs (18.9\%): 14 (51.8\%) attending undergraduate courses and 13 (48.2\%) in postgraduate courses. Of the 26 (76.4\%) nurse specialists, 14 (41.2\%) had more than one postgraduate degree, 21 (80.8\%) had expertise in intensive care, and of these, nine (42.9\%) in intensive pediatric and neonatal care. Of the 109 technicians, 14 (12.8\%) had graduated in nursing and five (4.6\%) had a postgraduate degree.

Regarding the institutional education policy, 130 (91\%) participants reported that the hospital offered many training programs, but 110 (77\%) said that there were few training offers for professionals before they took on new responsibilities in a different sector, and 87 (61\%) said they were allowed to perform the training, except for NICU 5, where 10 (83.3\%) participants mentioned that they were not allowed to participate in these activities. Regarding attendance in in-service education activities and the importance attributed to the topic, 137 (96\%) and 131 (91.6\%) participants, respectively, gave positive answers.

Regarding the relevance of working in a health team trained and qualified in intensive care, 109 (76.2\%) participants mentioned that it is extremely important and 125 (87.4\%) considered their own professional qualification to be sufficient. When asked to attribute importance to factors associated with the occurrence of AEs, professional qualification was considered by the participants as the most important factor to prevent these events $(n=76,53.1 \%)$. All hospitals had a Hospital Infection Control Service and a Quality and Patient Safety Center, and two hospitals (2 and 3) did not offer Continuing Education Services.

As for the results regarding the AEs, analysis of 79 medical records resulted in the identification of 63 triggers in $32(40.5 \%)$ records. After analysis of the cases,30 AEs were confirmed in 22 patients: infection ( $n=12 ; 40 \%)$, skin lesion $(n=9 ; 30 \%)$, accidental extubation $(n=2 ; 6.7 \%)$, reintubation $(n=3 ; 10 \%)$, catheter loss $(n=1 ; 3.3 \%)$, catheter infiltration $(n=1 ; 3.3 \%)$, medication error $(n=1 ; 3.3 \%)$ and transfusion $(n=1 ; 3.3 \%)$. 
Table 2 - Prognostic factors and association between nursing professional qualification and adverse events. Curitiba, PR, Brazil, 2017-2018

\begin{tabular}{ccccccccccc} 
Hospital & 1 & 1 & 2 & 3 & 4 & 5 & OR & CI95\% & p-value \\
\cline { 2 - 5 } & ICU & NICU & PICU & NICU & NICU & mPICU & NICU
\end{tabular}

Qualification

General training

in ICU

Nurse specialist

ICU nurse specialist

Graduated technician

$\begin{array}{rrrrrrrrr}87.2 \% & 75.0 \% & 88.0 \% & 85.7 \% & 93.3 \% & 91.7 \% & 1.05 & (0.97,1.14) & 0.2301 \\ 30.8 \% & 37.5 \% & 20.0 \% & 28.6 \% & 13.3 \% & 25.0 \% & 0.98 & (0.92,1.03) & 0.4048 \\ 23.1 \% & 31.2 \% & 24.0 \% & 23.8 \% & 13.3 \% & 25.0 \% & 0.99 & (0.91,1.08) & 0.8250 \\ 17.9 \% & 25.0 \% & 28.0 \% & 4.8 \% & 6.7 \% & 25.0 \% & 1.01 & (0.96,1.07) & 0.6058\end{array}$

Participation in

training programs

\begin{tabular}{|c|c|c|c|c|c|c|c|c|c|}
\hline Always attends & $12.8 \%$ & $18.8 \%$ & $36.0 \%$ & $38.1 \%$ & $36.7 \%$ & $25.0 \%$ & 1.02 & $(0.98,1.07)$ & 0.3759 \\
\hline $\begin{array}{l}\text { Almost } \\
\text { always attends }\end{array}$ & $87.2 \%$ & $81.2 \%$ & $64.0 \%$ & $57.1 \%$ & $50.0 \%$ & $58.3 \%$ & 1.00 & $(0.97,1.03)$ & 0.8636 \\
\hline Frequency score & $1.3 \%$ & $1.9 \%$ & $3.6 \%$ & $3.3 \%$ & $2.3 \%$ & $0.83 \%$ & 1.51 & $(0.92,2.48)$ & 0.1018 \\
\hline \multicolumn{10}{|c|}{ In-service education } \\
\hline $\begin{array}{l}\text { Continuing } \\
\text { Education Service }\end{array}$ & 1.0 & 1.0 & 0.0 & 0.0 & 1.0 & 1.0 & 0.25 & $(0.08,0.74)$ & 0.0121 \\
\hline
\end{tabular}

Source: Research data.

$\mathrm{OR}=$ odds ratio; $\mathrm{Cl}=$ confidence interval. 


\section{DISCUSSION}

The results showed that the nursing team seeks to improve their qualification through graduation, specialization and training in intensive care, and corroborate data published by the Federal Council of Nursing in Brazil, which reported that approximately one third of nursing technicians have a college degree, with emphasis to those with higher education in nursing (63.7\%). As for the nurses, $72.8 \%$ have specialization. Such data, consistent with the profile of Brazilian nursing ${ }^{(15)}$ reiterate that these professionals constantly seek qualification, without neglecting their work activities and other routine activities, e.g. those related to their families ${ }^{(15)}$.

Qualification in intensive care, which was found in part of the team, corroborates a North American study that emphasizes the importance of specialization among neonatal nurses, in line with the recommendations of the National Perinatal Association, inserted in the policy for the promotion of quality indicators in health ${ }^{(16)}$. However, despite these international recommendations, about $30 \%$ of the nurses who participated in this study were not specialists in their area of expertise.

Thus, it is necessary to advance on this issue and encourage institutional discussions to provide opportunities and time to enable qualification and ensure care based on the best evidence, as $83.3 \%$ of health professionals in NICU 5 reported low hospital management collaboration in the participation in educational/training activities.

Regarding continuing education activities, according to the participants' perception, hospitals offer training, but not at the time of admission to the service. Thus, there should be a greater concern about the need to ensure safe conditions to workers in their workplace and provide high quality care. The importance of training is emphasized here, especially when it comes to caring for seriously ill patients who are vulnerable to the various specialized and invasive procedures performed in ICUs.

Nurses have a generalist formation. Therefore, formal qualification for the care of critically ill patients, as well as frequent updates, through training and qualifications compatible with the demands of the service and collective gaps in knowledge are necessary. An interactive approach that considers the experience and expectations of learners is an essential aspect of good educational attainment and the transition to care practice.

In the present study, there was a prevalence of professionals who reported participating, always or almost always, in the training programs offered, and who attributed importance to it and considered themselves qualified in the care of critically ill patients hospitalized in neonatal and pediatric care units. In all the health units investigated, professional qualification was mentioned as the most relevant factor for the prevention of AEs, expressing the value attributed to it, which partially justifies the fact that most professionals participated in training courses/

Therefore, it is necessary to expand theoretical and practical knowledge in order to prevent and reduce AEs, especially those of infectious origin, as this was the type of disease prevalent in the study sample. This finding contrasts with the one obtained in the analysis of AEs that occurred in the mPICU of a Brazilian teaching hospital. Of the 73 cases identified, 18 (25\%) were related to the loss of a peripherally inserted central catheter. Continuing education activities and staff training were identified as strategies to reduce the recurrence of these problems $s^{(5)}$.

Although AEs related to medication administration are the most frequent occurrences in health services, including $\mathrm{NICUs}$ and PICUs ${ }^{(2)}$, this problem was detected in a single patient in the present study. It is inferred that these events may have been underreported in the investigated units, as their identification directly depends on the quality/reliability of the information in the medical records.

On the other hand, it is believed that the low prevalence of these AEs is related to the length of professional experience and the qualification of workers for neonatal and pediatric care, as newly graduated professionals and teams not trained and not familiar with institutional safety policies were described as factors that contributed to the events arising from the use of medications ${ }^{(2)}$.

Thus, providing continuing education activities aimed at preventing the recurrence of detected AEs, among others, contributes to the formation of a culture of patient safety and to the reduction of cases. In this context, a study with 375 nurses from nine NICUs and the mobile emergency service for newborns conducted in Australia found that these professionals obtain qualification through theoretical experience, mediated by workshops and conferences, among other educational strategies, and, mainly by individual practical or guided by senior nurses ${ }^{(17)}$. Lack of knowledge is the second cause of errors related to the process of medication administration ${ }^{(18)}$. It is known that these errors are not only associated with the tasks performed by the nursing team.

However, nursing is the professional occupation most actively engaged in the detection of errors, and these 
professionals handle the consequent notifications and develop various actions to prevent these problems. Although knowledge is perceived as an important element for the prevention of errors, researchers recognize that the knowledge of nursing professionals, particularly of nurses, is unsatisfactory ${ }^{(18)}$.

This finding reinforces the need for constant training/ educational processes ${ }^{(18)}$, as well as the structuring of specific units with material and human resources in sufficient quantity and quality to conduct continuing education actions that impact, in the medium and long term, the quality of the services provided to hospitalized patients.

Therefore, ensuring good care practices requires proactive actions, such as professional training, investments in safe communication and debates on "patient safety" among the teams. These measures contribute to the positive construction of a safety culture, in order to encourage a favorable organizational environment and understand and manage errors ${ }^{(19)}$.

A study with 128 nurses from six ICUs found that almost half of these professionals had low perception of the factors that favor risks and cause AEs. This finding reinforces the need to include this topic in academic curricula at all levels of professional training ${ }^{(20)}$.

Since the launch of the National Program for Patient Safety in 2013 was a landmark in the establishment of basic protocols for the promotion of patient safety in Brazil, it can be inferred that specific content needs to be addressed in institutional continuing education activities, in order to fill gaps and contribute to the dissemination of scientific evidence. The importance of training professionals based on the guidelines of policies aimed at ensuring patient safety is undeniable.

However, it is known that certain limitations, both in pedagogical projects and practices and in the persistent use of traditional methodologies for training/qualification of professionals in health services, impact the desirable effects in clinical practice. After all, these problems strengthen the disciplinary power of the management team and do not promote critical reflection ${ }^{(21)}$, which does not favor professionals'reflections on their care practices and the consequent changes in their perceptions and behaviors that result in patient unsafety.

The different characteristics investigated for the promotion of safe care by the nursing staff include education and experience. However, the results are the most diverse, and this is due to the different ways of measuring and analyzing the training and practices of continuing education in the studies, as well as the variables and outcomes listed by these studies ${ }^{(22)}$.

The fact that nursing technicians intend to pursue their studies was reported by the survey of the Brazilian Federal Council of Nursing and corroborates the results of the present study, demonstrating the interest of these individuals in professional qualification and career development. As for the type of qualification or training, $93.1 \%$ of the team reported attending these activities ${ }^{(15)}$.

It was found that many technicians have graduated or are attending higher education, and nurses have a postgraduate degree in health (latu sensu). In addition, most professionals participate in training programs. This data emphasizes the value attributed by the nursing team to qualification and training, which are important factors to improve the care and protection of patients.

Since the investment to offer qualification, training and the permanent education service contributes to continuous improvements in the work processes of the hospital service, a gap was identified in two of the surveyed hospitals, which also have the role of training future professionals. Continuing education is identified as one of the most important measures to promote patient safety ${ }^{(23)}$, whose results are reiterated by the present study. Therefore, the establishment of a service aimed at continuing education is considered essential.

\section{CONCLUSION}

The existence of a continuing education service, relevant to the qualification of nursing professionals, is a protective factor for the occurrence of adverse events among neonatal and pediatric patients in public hospitals in Paraná. Training to work in ICUs, qualification with specialization for nurses, graduation for nursing technicians and attendance to training programs were not predictors of protection against the occurrence of adverse events.

This study contributes to highlight the importance of a formal continuing education service in the hospital environment as an element of risk management aimed at professional qualification and protection of critically ill neonatal and pediatric patients. Low occupancy rates for some hospital ICU beds and the difficulty in identifying the topics addressed in training programs were some limitations of this study. 


\section{REFERENCES}

1. Ministério da Saúde (BR). Agência Nacional de Vigilância Sanitária. Resolução RDC n 7, de 24 de fevereiro de 2010. Dispõe sobre os requisitos mínimos para funcionamento de Unidades de Terapia Intensiva e dá outras providências. Diário Oficial União. 2010 fev 25 [cited 2021 May 3];147(37 Seção 1):4851. Available from: https://pesquisa.in.gov.br/imprensa/jsp/visualiza/index. jsp?data=25/02/2010\&jornal=1\&pagina=48\&tota|Arquivos=72.

2. Alghamdi AA, Keers RN, Sutherland A, Carson-Stevens A, Ashcroft DM. A mixedmethods analysis of medication safety incidents reported in neonatal and children's intensive care. Pediatr Drugs. 2021;23(3):287-97. doi: https://doi.org/10.1007/ s40272-021-00442-6.

3. World Health Organization. The conceptual framework for the international classification for patient safety. 2009 [Internet]. Geneva: WHO; 2009 [cited 2021 May 4]. Available from: http://www.who.int/patientsafety/taxonomy/ icps_full_report.pdf

4. Stockwell DC, Landrigan CP, Toomey SL, Loren SS, Jang J, Quinn JA, et al. Adverse events in hospitalized pediatric patients. Pediatrics. 2018;142(2):e20173360. doi: https://doi.org/10.1542/peds.2017-3360.

5. Silva CB, Silva DG, Carvalho LL, Goulart CL, Silva ALG, Angri D. Ocorrência de eventos adversos em unidade de terapia intensiva neopediátrica. R Epidemiol Control Infec. 2017;7(4):241-5. doi: http://doi.org/10.17058/reci.v7i4.7564.

6. Jesus AM, Morais CR, Almeida HOC. Eventos adversos relacionados à assistência em serviços de saúde: um desafio para segurança do paciente. Cad Grad Ciênc Biol Saúde Unit. 2020 [cited 2021 Fev 20];6(2):11-22. Available from: https:// periodicos.set.edu.br/cadernobiologicas/article/view/7228/4195

7. Carvalho DP, Rocha LP, Barlem JGT, Dias JS, Schallenberger CD. Workloads and nursing workers' health: integrative review. Cogitare Enferm. 2017;22(1):01-10. doi: http://doi.org/10.5380/ce.v22i1.46569.

8. Cho E, Sloane DM, Kim EY, Kim S, Choi M, Yoo IY, et al. Effects of nurse staffing, work environments, and education on patient mortality: an observational study. Int J Nurs Stud. 2015;52(2):535-42. doi: http://doi.org/10.1016/j.ijnurstu.2014.08.006.

9. SlusherTM, Kiragu AW, Day LT, Bjorklund AR, Shirk A, Johannsen C et al. Pediatric critical care in resource-limited settings-overview and lessons learned. Front Pediatr. 2018;6:49. doi: https://doi.org/10.3389/fped.2018.00049.

10. Mueller BU, Neuspiel DR, Fisher ERS. Principles of pediatric patient safety: reducing harm due to medical care. Pediatrics. 2019;143(2):e20183649. doi: https://doi. org/10.1542/peds.2018-3649.

11. Kaleci E, Arslan FT. Patient safety related implementations of nurses working in the neonatal intensive care unit and related factors. J Pediatr Res. 2020;7(1):18-24. doi: https://doi.org/10.4274/jpr.galenos.2019.00921.

12. Cassiani SHB, Lira Neto JCG. Nursing perspectives and the "nursing now" campaign. Rev Bras Enferm. 2018;71(5):2351-2. doi: https://doi. org/10.1590/0034-7167.2018710501.
13. National Health Service. Institute for Innovation and Improvement. Safe Care: improving patient safe. The Paediatric Trigger Tool for Measuring Adverse Events (UK version) [Internet]. United Kingdom: NHS, 2010 [cited 2019 Jan 29]. Available from: http://www.ihi.org/resources/Pages/Tools/ PaediatricTriggerToolUK.aspx.

14. Maziero ECS. Condições de trabalho da Enfermagem e ocorrência de eventos adversos em UTI Neopediátricas: um estudo de associação [tese]. Curitiba: Universidade Federal do Paraná; 2019 [cited 2019 Jan 29]. Available from: https://acervodigital.ufpr.br/bitstream/handle/1884/62083/R\%20 -\%20T\%20-\%20ELIANE\%20CRISTINA\%20SANCHES\%20MAZIERO. pdf? sequence $=1 \&$ is Allowed $=\mathrm{y}$.

15. Conselho Federal de Enfermagem [Internet]. Pesquisa perfil da Enfermagem no Brasil: banco de dados. 2013 [cited 2020 Jun 22]. Available from: http://www. cofen.gov.br/perfilenfermagem/index.html.

16. Purdy IB, Melwak MA, Smith JR, Kenner C, Chuffo-Siewert R, Ryan DJ, et al. Neonatal nurses NICU quality improvement: embracing EBP recommendations to provide parent psychosocial support. Adv Neonatal Care. 2017;17(1):33-44. doi: https://doi.org/10.1097/ANC.0000000000000352.

17. Spence K, Sinclair L, Morritt ML, Laing S; The NSW Neonatal Clinical Nurse Consultants Network. Knowledge and learning in speciality practice. J Neonatal Nurs. 2016;22(6):263-76. doi: https://doi.org/10.1016/j.jnn.2016.05.002.

18. Menegueti MG, Garbin LM, Oliveira MP, Shimura CMN, Guilherme C, Rodrigues RAP. Errors in the medication process: proposal of an educational strategy based on notified errors. J Nurs UFPE. 2017 [cited 2020 Jun 21];11(Suppl. 5):2046-55. Available from: https://periodicos.ufpe.br/revistas/revistaenfermagem/article/ viewFile/23358/18979.

19. Duarte SCM, Azevedo SS, Muinck GC, Costa TF, Cardoso MMVN, Moraes JRMM. Best safety practices in nursing care in neonatal intensive therapy. Rev Bras Enferm. 2020;73(2):e20180482. doi: https://doi.org/10.1590/0034-7167-2018-0482.

20. Lobão WM, Menezes IG. Atitude dos enfermeiros e predisposição da ocorrência de eventos adversos em unidade de terapia intensiva. Rev Enferm UFPE. 2017 [cited 2020 Jun 22];11(Supl. 5):1971-9. Available from: https://periodicos.ufpe. br/revistas/revistaenfermagem/article/viewFile/23350/18963.

21. Silva CPG, Aperibense PGGS, Almeida Filho AJ, Santos TCF, Nelson S, Peres MAA. From in-service education to continuing education in a federal hospital. Esc Anna Nery. 2020;24(4):e20190380. doi: https://doi. org/10.1590/2177-9465-ean-2019-0380.

22. Abadi MBH, Akbari H, Akbari H, Gholami-Fesharaki M, Ghasemi M. The association of nursing workloads, organizational, and individual factors with adverse patient outcome. Iran Red Crescent Med J. 2017;19(4):e43444. doi: https://doi. org/10.5812/ircmj.43444.

23. Silva ACA, Silva JF, Santos LRO, Avelino FVSD, Santos AMR, Pereira AFM. Patient safety in the hospital context: an integrative literature review. Cogitare Enferm. 2016;21(esp):1-9. doi: http://doi.org/10.5380/ce.v21i5.37763. 


\section{- Authorship contribution:}

Conceptualization - Eliane Cristina Sanches Maziero;

Elaine Drehmer de Almeida Cruz; Josemar Batista;

Francine Taporosky Alpendre.

Formal analysis - Elias Teixeira Kraiski.

Investigation - Eliane Cristina Sanches Maziero;

Francine Taporosky Alpendre.

Methodology - Eliane Cristina Sanches Maziero; Elaine

Drehmer de Almeida Cruz; Elias Teixeira Kraiski.

Project administration - Elaine Drehmer de Almeida

Cruz.

Supervision - Eliane Cristina Sanches Maziero; Elaine

Drehmer de Almeida Cruz.

Validation - Marilise Borges Brandão; Elias Teixeira

Kraiski; Francine Taporosky Alpendre.

Visualization - Eliane Cristina Sanches Maziero; Josemar Batista.

Writing - original draft - Eliane Cristina Sanches

Maziero; Elaine Drehmer de Almeida Cruz; Josemar

Batista.

Writing - review and editing - Eliane Cristina Sanches

Maziero; Elaine Drehmer de Almeida Cruz; Josemar

Batista.

The authors declare that there is no conflict of interest.

\section{- Corresponding author:}

Eliane Cristina Sanches Maziero.

E-mail: elicris_maziero@yahoo.com.br

Associate editor:

Wiliam Wegner

Maria da Graça Oliveira Crossetti 